\title{
On the formation of collective memories: The role of a dominant narrator
}

\author{
ALEXANDRU CUC \\ Nova Southeastern University, Fort Lauderdale, Florida \\ YASUHIRO OZURU \\ University of Memphis, Memphis, Tennessee \\ DAVID MANIER \\ City University of New York, New York, New York \\ and \\ WILLIAM HIRST \\ New School University, New York, New York
}

\begin{abstract}
To test our hypothesis that conversations can contribute to the formation of collective memory, we asked participants to study stories and to recall them individually (pregroup recollection), then as a group (group recounting), and then once again individually (postgroup recollection). One way that postgroup collective memories can be formed under these circumstances is if unshared pregroup recollections in the group recounting influences others' postgroup recollections. In the present research, we explored (using tests of recall and recognition) whether the presence of a dominant narrator can facilitate the emergence of unshared pregroup recollections in a group recounting and whether this emergence is associated with changes in postgroup recollections. We argue that the formation of a collective memory through conversation is not inevitable but is limited by cognitive factors, such as conditions for social contagion, and by situational factors, such as the presence of a narrator.
\end{abstract}

Members of a group often come to remember their past similarly. Since Halbwachs (1980) first described the phenomenon, it has garnered a great deal of attention, in large part because it bears critically on issues of national identity and ethnic conflict, as well as group cohesion and family stability (Fentress \& Wickham, 1992; Olick \& Robbins, 1998). Although collective memories have been studied mainly by sociologists, who have focused on the role of powerful institutions in shaping the content of collective memories, in a limited body of work a psychological perspective has been adopted (see Bangerter, von Cranach, \& Arn, 1997; Bar-Tal, 2000; Echterhoff \& Saar, 2002; Gladwell, 2002; Middleton \& Edwards, 1990; Pasupathi, 2001; Pennebaker, Paez, \& Rime, 1997;

The first three authors contributed equally to this project. The order in which they are listed reflects the throw of a die. We gratefully acknowledge the support of a grant from the James S. McDonnell Foundation and NIMH Grant MH066972. We thank Ovidiu Margineanu, Roxana Paziuc, Dora Rotaru, and, particularly, Alin Coman for help in collecting and analyzing the data and Robert Meksin for editorial advice. Correspondence should be addressed to A. Cuc, Department of Behavioral Sciences, Farquhar College of Arts and Sciences, Nova Southeastern University, 3301 College Avenue, Fort Lauderdale, FL 33314 (e-mail: calex@nova.edu).

Note-This article was accepted by the previous editorial team, when Colin M. MacLeod was Editor.
Weldon, 2001; Wertsch, 2002). One line of such research has followed Sherif's (1966) work on social norms and Sperber's (1996) discussion of the epidemiology of beliefs and has treated collective memories as shared individual memories (see also Hirst \& Manier, 1996; Olick, 1999). From this perspective, both core and central elements and the peripheral details of a story can constitute a collective memory if they are shared. (For instance, the song "Yankee Doodle Dandy" may be considered part of American collective memory, but it is not central to most narratives one would tell about the United States.)

A critical question is how initially dissimilar individual (i.e., unshared) recollections become shared. In this article, we investigate the influence that conversations have on this process, examining what has been variously called collaborative remembering, conversational remembering, or group recounting. Psychologists have recently studied the processes underlying collaborative remembering (for reviews, see Pasupathi, 2001; Weldon, 2001). Our interest here is in the influence that collaborative remembering has on subsequent remembering and whether this influence leads to the formation (or further formation) of a collective memory. We especially want to determine whether the proportion of shared recollections in the individual recollections following an act of conversational remembering (shared postgroup recollections) is greater than the proportion found for recollections offered prior to the con- 
versation (shared pregroup recollections). It is well established that unshared pregroup recollections surfacing in a group recounting can influence the postgroup recollections of other group members, either by reminding group members of forgotten information or by contaminating the subsequent recollections (the latter is referred to as social contagion; see Basden, Basden, \& Henry, 2000; Gabbert, Memon, \& Allan, 2003; Loftus, 1993; McCann \& Higgins, 1992; Meade \& Roediger, 2002; Roediger, Meade, \& Bergman, 2001; Todorov, Lalljee, \& Hirst, 2000; Walther et al., 2002; Weldon, 2001; Wilkes-Gibbs \& Kim, 1991; Wright, Self, \& Justice, 2000).

It is less clear whether conversations are likely to produce an increase in the proportion of shared postgroup recollections. A conversation could induce group members to forget some shared items, perhaps because of interference between their original memory and what was said in the conversation. Consequently, memories that were initially shared could come to be shared less as a result of the conversation. A conversation may not further the formation of a collective memory if this change occurs at a faster rate than does the transformation of unshared into shared items.

A few studies suggest that this alternative is unlikely. For instance, Weldon (2001) showed that postgroup recollections across a group can converge onto core, or central, elements of a story. She did not, however, explicitly examine whether this convergence leads to a greater proportion of shared elements. On the other hand, Wright et al. (2000; see also Gabbert et al., 2003) found that group recounting can lead to a greater number of shared postgroup recollections, but they focused only on one critical item and confined themselves to groups consisting of only 2 individuals. Other studies have not assessed whether mnemonic convergence occurs outside the confines of the group recounting itself (e.g., Walther et al., 2002).

In the present study, we sought more definitive evidence that conversational remembering leads to the formation of a collective memory, now looking at groups of 4 and explicitly tracking the transformation of unshared pregroup recollections into shared postgroup recollections. More importantly, the conditions under which conversational remembering furthers the formation of a collective memory were examined. To the extent that reminding and social contagion underlie the formation of a collective memory, factors affecting these processes would be likely to influence the formation of a collective memory as well. When it comes to social contagion, the factors would include the presence of a warning about possible group influence (Meade \& Roediger, 2002), the degree of difficulty group members experience in monitoring the source of a memory (Ozuru \& Hirst, 2002), the size of the group (Walther et al., 2002), and the level of dissension within a group (Walther et al., 2002).

According to our definition of collective memory, there is another factor that also deserves attention - that is, that the formation of a collective memory should be influenced by the introduction of unshared pregroup recollec- tions into the group recounting. These unshared pregroup recollections could, in turn, lead to more shared postgroup recollections. Surprisingly, according to Stasser, Wittenbaum, and their colleagues, this condition for the formation of a collective memory should rarely be satisfied, inasmuch as conversational participants tend to discuss shared information, known to all participants, rather than unshared information, known only to one member (Wittenbaum \& Park, 2001; Wittenbaum \& Stasser, 1996; cf. Tindale \& Sheffey, 2002).

One exception to the Stasser-Wittenbaum principle is that when a group member is viewed as an expert, his or her unshared facts are more likely to emerge in a group discussion than when members are viewed as equals (Stasser, Stewart, \& Wittenbaum, 1995; Stewart \& Stasser, 1995; cf. Moreland, Argote, \& Krishman, 1996; Wegner, 1986; Wegner, Erber, \& Raymond, 1991). A related exception is that even in conversations among peers, a person dominating a discussion (the narrator) may tend to introduce his or her unshared pregroup recollections into group recountings. According to the model advanced by Stasser, Wittenbaum, and their colleagues, the more someone speaks, the more likely they should be to utter something unshared (Stasser \& Titus, 1987). Our claim about narrators follows from this postulate. It is also consistent with research showing that the presence of a narrator can have an important influence on the outcome of nonmnemonic tasks (Fay, Garrod, \& Carletta, 2000).

Interestingly, narrators are often, but not always, present in group recountings (Basden, Basden, Bryner, \& Thomas, 1997; Basden et al., 2000; Basden, Reysen, \& Basden, 2002; Hirst \& Manier, 1996; Hirst, Manier, \& Apetroaia, 1997; Manier, 1997; Manier, Pinner, \& Hirst, 1996; Weldon \& Bellinger, 1997). Consequently, if narrators make the contribution we are proposing, conversations may be more likely to convert unshared pregroup recollection into shared postgroup recollection than the work of Stasser, Wittenbaum, and colleagues suggests. We, therefore, sought to determine whether a narrator introduces unshared pregroup recollections into group recountings and whether, in doing so, the narrator creates a condition conducive to the formation of a collective memory.

We also wanted to explore whether the presence of a narrator affects the content of postgroup collective memories. Postgroup collective memories should not consist of all the pregroup recollections of a group, in that group recountings rarely contain all of them (see Weldon, Blair, \& Huebsch, 2000). Nor, as we will discuss below, would we expect postgroup collective memories to be a blending of pregroup individual memories, as when memories of yellow and blue blend to create a memory of green (Sherif, 1966; Wilkes-Gibbs \& Kim, 1991). More plausibly, postgroup collective memories may consist of the core and central elements of the original story, as Weldon (2001) asserted. This outcome would be expected to occur in the absence of a dominant narrator. In such a situation, mainly shared pregroup recollections would be expected to surface in the group recounting, and hence, the post- 
group collective memory should consist mainly of shared pregroup recollections. These shared elements should, in turn, be core and central elements, inasmuch as core and central elements are more likely to be remembered by multiple participants than are peripheral elements (Kintsch, 1976).

A postgroup collective memory could also consist of not just shared or core and central elements, but also the unshared pregroup recollections of one group member (Wright et al., 2000). This alternative is more likely to arise if a dominant narrator is present in the group recounting. In this case, unshared pregroup recollections would be likely to surface in a group recounting, and these, in turn, could be transformed into increased numbers of shared postgroup recollections.

We explored, then, whether the presence of a dominant narrator would affect the formation of a collective memory and its content, using, in Study 1, a recall test and, in Study 2, a recognition test. We focused on memories for directly experienced, nonhistorical events - specifically, the event of reading a story. In doing so, we avoided terminological confusions in the literature, where the term collective memory refers, in different instances, to historical events, directly experienced events, or events learned about secondhand (Hirst \& Manier, 2002). In pilot work in which we employed a professional actor to serve as the dominant narrator, participants reported that they felt that the conversations were stilted and awkward. Consequently, we allowed a dominant narrator to emerge naturally from spontaneous conversation, resulting in conversations that approximated naturally occurring conversations.

\section{STUDY 1}

We asked participants to study two stories and then to recall them, first individually, second as a group, and finally individually once again. In our data analyses, we carefully tracked the transformation of unshared pregroup individual recollections into shared postgroup individual recollections.

\section{Method}

Participants. We tested 24 Romanian families. We examined families because we expected that family members would naturally adopt conversational roles. As for the use of Romanian participants, three of the authors were spending time in Romania, with one being a native speaker of Romanian. The families were recruited through advertising in local newspapers. Each family was paid for its participation. Each family consisted of two parents and two adolescent children. Fifteen families had a girl and a boy, 6 families had two boys, and 3 families had two girls. The average age for the parents was 46 years; the children's average age was 18 years (ranging from 14 to 25 ).

Stimulus Materials. We selected two short stories that were not familiar to any of the participants. The first story was a 1,053-word translation of Jerome K. Jerome's (1900) "Three Men on the Bummel," which describes the author's travels through Germany. The second story was a 945-word translated segment from Paul Coelho's (1993) “The Alchemist," consisting of a dialogue between an adolescent and an old man about religion, love, and wisdom.
Design and Procedure. There were three sessions, spaced a week apart. When individual recollections were called for, the participants were placed in separate rooms. We openly audiotaped all the individual recollections and group recountings. In Session 1, the family members read the stories at their own pace, with the understanding that they would later have to discuss them with other family members. The order in which the family members read the two stories was counterbalanced across families. After the family members had talked to each other for 20 min about a recent family celebration (e.g., a birthday), they individually recalled aloud each of the two stories, after each story had been identified by its title. They were told to remember the story as accurately as possible and in as much detail as possible and were pressed, at the end, to provide assurance that they had recalled as much as they could. The stories were recalled in the order in which they had originally been studied.

In Session 2, the family members were assembled as a group and were asked to recount the first story that they had studied, again identified by title. The family members were then placed in separate rooms and, following the procedure in the first session, were asked to recollect individually the second story (the control individual recollection). One week later, the family members were asked once again to recollect individually the two stories.

Coding. We transcribed all the audiotape recordings and then checked the accuracy of the transcription against the audiotapes, employing an individual naive to the experimental aims. Details can be found elsewhere (Hirst \& Manier, 1996; Manier, 1997). Suffice it to say for the present that, following Dritschel (1991) and Bangerter (2000), we first divided the transcribed texts into what we will call structural units and then subdivided these into subunits, some of which were narrative and some nonnarrative. Narrative units describe events or states that are linked together (causally, temporally, or spatially); that is, they tell the story of a central topic or theme. A single narrative unit consists of a subject (perhaps implicit) and a predicate, describing a single state, action, or event. It may include temporal modifiers and other descriptive phrases but may not describe an additional state, event, or action (usually signaled by the presence of an additional verb). All structural units not fitting this definition (e.g., questions and off-topic statements) were coded as nonnarrative units.

The next stage of coding involved a series of comparisons, made by two independent coders, of narrative units to determine whether they "meant the same thing." The coders were told to score for gist. If a narrative unit was "She put the green ball on the table," the coders scored as "meaning the same thing" the phrase "She put the ball on the table," giving it a full point. When an incidental detail was wrong but the gist was preserved, as in "She put the red ball on the table," the coders gave the unit half point. The comparisons were among the original stories, the pregroup recollections, the group recounting, and the postgroup recollections. In all stages and all comparisons, $\kappa$, a measure of interrater reliability, was greater than .75 (Fleiss, 1981). We asked the two coders to resolve any disagreements.

In order to determine whether a dominant narrator was present and, if so, who the dominant narrator was, we first devised a measure of the extent to which each individual in the group narrated. In developing this measure, we kept in mind the possibility that some conversational participants who dominated the narrating might also utter a large number of nonnarrative utterances, whereas others might confine themselves to narrating. Thus, we measured strength as narrator as follows:

strength as narrator $=[$ (the proportion of the participant's narrative units out of the total number of structural units he or she contributed) + (the proportion of the participant's narrative units out of all narrative units in the conversation)]/2.

We considered another measure of strength as narrator, which focused entirely on the degree to which a participant dominated the 
narration in the group. The Pearson product-moment correlation between the two measures was $r=.92, p<.001$. Moreover, when we substituted the one- for the two-dimensional measure in the analyses below, the results did not differ. We will focus the discussion here on the two-dimensional measure.

After developing a measure of a group member's strength as narrator, we then sought to determine whether a dominant narrator was present in the group recounting. Here, we contrasted the highest strength-as-narrator with the average strength-as-narrator scores of the other family members, to obtain what we will refer to as mean strength as narrator (MSN) - that is, MSN = (strength of individual with highest strength as narrator) - (average of strength as narrator of all other family members).

Although this measure appropriately treats the group members dominance as narrators as a matter of degree, we also made a qualitative classification of groups as possessing or not possessing a dominant narrator. We categorized the 24 families we tested as to whether they belonged to either a high-MSN group (above the median MSN score) or a low-MSN group (below the median). As we will use the term in this article, a dominant narrator is present in the high-MSN groups and absent in the low-MSN groups.

Measure of centrality. We asked 18 Romanian students enrolled at Babes-Bolyai University, Cluj, Romania, who were naive to the study, to specify for each idea unit of the story whether it was "core or central to the story." For each story, they first read it in its entirety and then rated each idea unit on a scale from 1 to 10 , with 1 indicating that the unit was extremely peripheral to the story and 10 that it was extremely core or central to the story. The order of the stories was counterbalanced across raters. For each idea unit, we averaged over the raters' responses and treated this average as the centrality score of the idea unit.

\section{Results}

In what follows, we first will discuss the pregroup individual recollections, then the group recountings (and the control individual recountings), and finally the postgroup individual recollections. In many of the analyses, we are comparing the performance of groups across conditions; however, in some instances, we are interested in the performance of individuals within the group. In the latter instances, performance scores may not be independent of each other, thereby undermining a key assumption underlying ANOVAs. Because of this concern, Kashy and Kenny (2000) have suggested that researchers should examine intraclass correlations to determine whether interdependency exists and, if it does, to account for this interdependency in the statistical analysis. According to this method, if a significant level of intraclass correlation is found for the scores, groups, instead of individuals, should be treated as the units of analysis. In testing the significance of an intraclass correlation, we adopted a liberal criterion $(\alpha=.2)$, following Kashy and Kenny's recommendation. (We will report results from the intraclass correlations analyses only when they indicated that we should treat individuals as the units of analysis, since the default is to treat groups as the unit.)

Pregroup individual recollections. Pregroup individual recollections consisted, on the average, of 292.1 words and 37.8 narrative units. The participants told substantially different stories in the pregroup recollections, when the details are considered. Family members recalled an average of $18 \%$ of the narrative units in the original stories. Averaging over families and stories, we found that
$56 \%$ of the total number of distinct narrative units in all pregroup recollections were found in only one of the pregroup recollections, $24 \%$ in two, $16 \%$ in three, and only $4 \%$ in all four recollections.

As was expected, shared narrative units were more core, or central, than were unshared narrative units. Using the centrality ratings as the dependent measure, we found a main effect for the degree of sharedness $[F(1,23)=$ 29.88, $\left.M S_{\mathrm{e}}=11.6, p<.001\right]$. Recollections shared by 4 family members had an average centrality rating of 6.61 ; by 3 family members, 5.94; by 2 family members, 5.63; and by only 1 family member, 5.68 .

Group recounting. In 17 groups, 1 and only 1 person in a conversation had a strength-as-narrator score of .25 or better. In the other 7 groups, 2 family members scored .25 or better. All but 2 of the participants in the present study had a strength-as-narrator score greater than 0 , indicating that almost everyone narrated, at least to a small extent. We did not find either gender or family role (parent vs. child) to be a good predictor of conversational roles; dominant narrators included sons, daughters, mothers, and fathers.

As to the MSN scores, the strength-as-narrator score of the strongest narrator in the high-MSN groups was, on average, .38 , with scores ranging from .27 to .71 . The strength-as-narrator score of the strongest narrator in the low-MSN groups was, on average, .20, with scores ranging from .14 to .27 .

We predicted that the proportion of unshared pregroup narrative units emerging in the group recounting should be greater in the high-MSN groups than in the low-MSN groups and that these unshared pregroup narrative units should be mainly those of the dominant narrator. To test these predictions, we calculated, for each family member, his or her proportion of unshared pregroup narrative units in the group recounting out of the total number of narrative units in the group recounting (see Table 1). Using this measure, a significant interaction between the size of the MSN of a group (low vs. high MSN) and the role of the family member in the group (strongest narrator vs. others) emerged $\left[F(1,22)=7.99, M S_{\mathrm{e}}=0.01, p<.01\right]$. As for shared pregroup narrative units, the size of the MSN did not matter.

Postgroup individual recollections. We were interested in whether conversational remembering promotes the formation of a collective memory. To test this, we

Table 1

Distribution of Narrative Units in the Group Recounting: Proportions of Unshared and Shared Pregroup Narrative Units Emerging in the Group Recounting Out of the Total Narrative Units in the Group Recounting

\begin{tabular}{cccc}
\hline & \multicolumn{2}{c}{$\begin{array}{c}\text { Unshared Pregroup } \\
\text { Recollections From }\end{array}$} & \\
\cline { 2 - 3 } Group & Strongest Narrator & Others & $\begin{array}{c}\text { Shared Pregroup } \\
\text { Recollections }\end{array}$ \\
\hline Low MSN & .14 & .08 & .68 \\
High MSN & .22 & .08 & .69
\end{tabular}

Note-MSN, mean strength as narrator. 
used a version of the definition developed in the introduction - namely, that a collective memory is formed if the overlap of postgroup recollections is greater than the overlap of pregroup recollections. We defined overlap as the number of narrative units shared across the recollections of 4,3 , or 2 members divided by the total number of semantically distinct narrative units in all four recollections (see Table 2). (Although our design is quasiexperimental, we retain the standard convention of referring to the conditions as experimental vs. control, with experimental referring to the condition of group recounting and control referring to the individual recollection condition.) We found main effects for condition [experimental vs. control; $\left.F(1,23)=4.37, M S_{\mathrm{e}}=0.05, p<.05\right]$ and time [pregroup vs. postgroup; $F(1,23)=10.05, M S_{\mathrm{e}}=$ $0.07, p<.01]$. More important, we found an interaction between condition and time $\left[F(1,23)=29.96, M S_{\mathrm{e}}=\right.$ $0.11, p<.001]$. This interaction suggests that a collective memory is more likely to emerge after a group recounting than after control individual recollections. Another way of stating this is that the recollections of the participants in group recountings lost their individualistic character from pregroup to postgroup.

One cannot determine from these overlap measures whether unshared pregroup recollections are, indeed, being transformed into shared postgroup recollections. The unshared recollections may simply be forgotten. In order to determine what happened to the unshared pregroup recollections, we traced them from pregroup to postgroup. We first calculated the proportion of a family member's unshared pregroup narrative units that emerged in his or her postgroup individual recollection (self-to-self transmission of narrative units). We then calculated the proportion of this individual's unshared pregroup recollections that emerged in the postgroup recollection of any of the other 3 family members (self-to-others transmission).

Intuitively, we might expect that any group member would be more likely to get a narrative unit from his or her pregroup recollections into his or her own postgroup recollection (self-to-self) than into other group members' postgroup recollections (self-to-others). We observed this pattern in the control condition. On average, $47 \%$ of the narrative units in a group member's unshared pregroup recollections overlapped with those in his or her own postgroup recollections, whereas only $12 \%$ of his or her unshared pregroup narrative units could be found in another group member's postgroup recollections $[t(23)=7.74$, $p<.001]$.
Table 2

Proportion of Narrative Units Shared by Family Members Out of Total Number of Narrative Units

\begin{tabular}{lcc}
\hline \multicolumn{3}{c}{ Out of Total Number of Narrative Units } \\
\hline Condition & $\begin{array}{c}\text { Pregroup } \\
\text { Recollection }\end{array}$ & $\begin{array}{c}\text { Postgroup } \\
\text { Recollection }\end{array}$ \\
\hline Experimental & .43 & .56 \\
Control & .45 & .43 \\
\hline
\end{tabular}

The more interesting data came from the experimental condition (see Table 3). We expected that the difference between the self-to-self score and the self-to-others score should be smaller for the strongest narrator in a family than for the other family members. Moreover, we expected that this effect should be greater for the high-MSN groups than for the low-MSN groups. Or to put it another way, there should be a three-way interaction among conversational role (strongest narrator vs. others), MSN (high vs. low), and type of score (self-to-self vs. self-to-other). In an ANOVA, we found the predicted three-way interaction $\left[F(1,22)=8.49, M S_{\mathrm{e}}=0.26, p<.008\right]$. Thus, dominant narrators were more likely than other family members to get their unshared pregroup recollections into others' postgroup recollections. Moreover, this advantage was greater to the extent that the dominant narrator was a member of a high-MSN group.

As to the content of the postgroup collective memories, first, we predicted that the postgroup collective memory should be more likely to consist of core and central elements for low-MSN groups than for high-MSN groups. In other words, low-MSN groups should have a larger measure of centrality than do high-MSN groups. If we define the postgroup collective memory conservatively as consisting of those recollections shared by 3 or 4 group members, we find that the average centrality rating for the postgroup collective memories was 6.00 for the highMSN groups and 6.38 for the low-MSN groups $[t(22)=$ $2.25, p<.05]$.

Second, we predicted that when a dominant narrator was present, the postgroup collective memory should resemble the dominant narrator's, with this resemblance being stronger for high-MSN groups than for low-MSN groups. We examined the overlap of the dominant narrator's recollection with the recollections of other family members (narrator/other overlap), as well as the overlap across the recollections of nonnarrators (other/other overlap). We define overlap here as the number of items two individuals have in common divided by the total num-

Table 3

Overlap Between Unshared Pregroup and Postgroup Recollections for the Experimental Condition: From Self to Self or From Self to Others

\begin{tabular}{cccccc}
\hline & \multicolumn{2}{c}{ Strongest Narrator } & & \multicolumn{2}{c}{ Other Family Members } \\
\cline { 2 - 3 } \cline { 5 - 6 } Group & Self to Self & Self to Others & & Self to Self & Self to Others \\
\hline Low MSN & .50 & .19 & & .42 & .16 \\
High MSN & .43 & .45 & & .46 & .12 \\
\hline
\end{tabular}

Note-MSN, mean strength as narrator. 


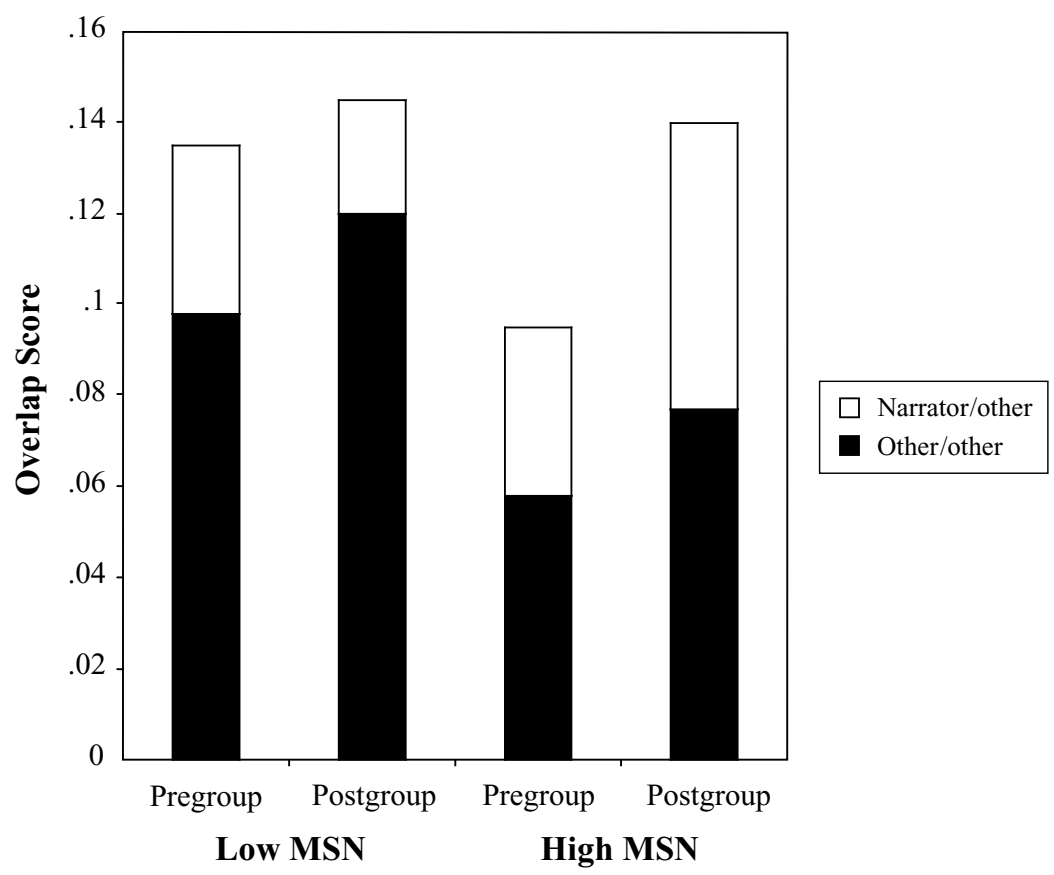

Figure 1. The difference between the other/other overlap scores and the narrator/ other overlap scores for the pregroup and postgroup recollections in the experimental condition, broken down by the size of the mean strength as narrator (MSN) of the group.

ber of semantically distinct narrative units uttered by the two group members. The narrator/other overlap was the average of the strongest narrator's overlap with each of the 3 other family members. The other/other overlap was the average of all possible pairings of the 3 other family members (see Figure 1). The difference between the narrator/other overlap and the other/other overlap should be greater for postgroup recollections than for pregroup recollections in the experimental condition, particularly as a function of the type of MSN group. We found the expected significant three-way interaction between type of overlap (narrator/other vs. other/other), condition (pregroup vs. postgroup), and MSN (high vs. low) $[F(1,22)=$ $\left.5.08, M S_{\mathrm{e}}=0.03, p<.05\right]$.

\section{Discussion}

The present results indicate that conversations can promote the formation of a collective memory but that this influence is associated with the presence of a dominant narrator. Even though group recountings often do not include unshared pregroup recollections (Wittenbaum \& Park, 2001), Study 1 showed that unshared pregroup recollections are likely to emerge in the group recounting to the extent that dominant narrators are present. The influence narrators have on the group recounting also shapes the content of postgroup collective memories. To the degree that dominant narrators are present, postgroup collective memories reflect their unique rendering of the past. To the degree that they are absent, they consist mainly of core and central elements.
We found no evidence that the postgroup collective memory was likely to be the sum of the individual pregroup recollections: Only $26.4 \%$ of the pregroup individual narrative units found their way into the postgroup collective memory. What about blendings? We did not directly probe for their presence, because it would have been challenging to determine the wide variety of possible blendings of the narrative elements of the original story. However, only $7 \%$ of the narrative units in the postgroup recollections failed to capture the gist of any of the narrative units in the pregroup recollections. This figure places an upper limit on the number of blendings in the postgroup recollections and suggests that there were few blendings in the postgroup collective memories that we collected. (The figure also indicates that few distortions were introduced into recollections through the group recounting process.) We might have found more blending if our material had allowed for graded responses (cf. Sherif, 1966; Wilkes-Gibbs \& Kim, 1991). However, it is worth noting that blendings have been shown to be difficult to detect in the postevent information literature (e.g., Belli, 1988).

Finally, it is possible that one member's unshared pregroup recollections emerged in other members' postgroup recollections as a result of reminiscence. This possibility seems unlikely, in that in the control condition, the participants recalled as many narrative units in their postgroup recollection $(M=153.2, S D=52.1)$ as in their pregroup recollection $(M=148.6, S D=45.3)$. Moreover, if we calculate the other/other overlap score, as outlined above, for the control condition, we do not find a significant dif- 
ference (pregroup other/other overlap, $M=.08, S D=$ .08 ; postgroup other/other overlap, $M=.08, S D=.06$ ).

\section{STUDY 2}

We sought to confirm the results of Study 1 by employing not only a postgroup free recall test, but also a postgroup recognition test. Moreover, we wanted to explore whether the effects we had observed extended to groups of unrelated individuals. Finally, we were concerned that the transformation of unshared pregroup recollections into shared postgroup recollections might have arisen not only because an item in the group recounting reminded the participants of a forgotten item, but also because of social contagion (cf. Basden et al., 2000). Consequently, we now asked unrelated participants to read stories with different versions of several details. For instance, in a story about an extramarital affair, the participants read that a couple met in a café, bar, Italian restaurant, or steakhouse, depending on which version of the story they were given. A recognition probe would consist of the version of one of the set of these contrasting details - for example, "Did the couple meet in (a) a café, (b) a bar, (c) an Italian restaurant, or (d) a steakhouse?" We were chiefly interested in whether recognition errors (false alarms) could be traced back to the conversation.

\section{Method}

Participants. Twenty male and 36 female English-speaking adults, recruited by a flyer posted around the New School University campus, were divided into groups whose members did not know each other. The participants were paid for their efforts.

Stimulus Materials. We constructed four short stories, with an average length of 438.3 words (range: $275-794$ words). For each story, we devised four different versions by changing story details. The stories were paired, with each pair of stories consisting of one story with four critical details and one story with six critical details.

For the recognition task, we devised a questionnaire booklet with a four-item forced choice recognition probe printed on each lettersize page. Each probe consisted of a brief question about a detail in the story, followed by four possible answers. For the 20 probes assessing the 20 sets of contrasting details, the probe consisted of the four different versions that the participants had read. For the 20 fourchoice recognition probes assessing noncontrasting details, the foils were constructed to be reasonable alternatives to the target item.

Design and Procedure. The procedure was similar to that in Study 1 . In order to ensure that the results from Study 1 did not depend on the retention intervals we used, we shortened them here. At the beginning of the experiment, in separate rooms, each participant read the four short stories for $20 \mathrm{~min}$ and then, as distraction, filled out a personality questionnaire for $20 \mathrm{~min}$; finally, he or she recalled individually all four stories. The next day, group members were introduced to each other and were instructed to get to know each other for $15 \mathrm{~min}$. After this warm-up period, they recalled two of the stories as a group. Afterward, they were ushered into separate rooms and were asked to recall individually the remaining two stories, one story at a time. The sequence (group recounting vs. control individual recollection) was counterbalanced, as was the assignment of the stories to the group recounting and individual recall conditions. A 20-min distraction task consisting of crypt-arithmetic problems followed. The participants then free-recalled all four stories. The recognition test was administered immediately after the individual free recall task.
In the recognition test, the participants were instructed to choose the item that they remembered from the text and to assign a confidence rating to each of their responses. We stressed that we wanted them to respond accurately with what was in the original text.

\section{Results}

There are four main results to be reported: (1) recognition memory, (2) confidence ratings, (3) individual free recall, and (4) the consensus among the postgroup individual recollections. The data of 2 participants were eliminated because these individuals had participated in a similar study.

Recognition. We transcribed the pregroup and postgroup recollections, as well as the group recounting, and then identified the presence of a contrasting detail in the transcript. The version in the group recounting had to be exactly as stated in the original story to count as a restatement of the original. Thus, if a participant said that the couple had met at a restaurant, it did not count as correct for a statement that the couple had met in an Italian restaurant. Two coders undertook this task, with a reliability measure of $\kappa=.83$. On average, $72 \%$ of at least one version of the critical details surfaced in the group recountings.

We confined the present analysis to those recognition probes made up of contrasting details, classifying the responses to the probes as hits, critical false alarms (participants falsely recognized a distractor that could be traced to the conversation), and random false alarms (participants falsely recognized a distractor that had no known source). We calculated a base rate in order to control for the possibility that more than one version of a contrasting detail appeared in the group recounting:

$$
\begin{aligned}
\text { base rate }= & (1.0-\text { experimental hit rate }) \times \text { average } \\
& \begin{array}{l}
\text { number of alternative versions of a } \\
\text { critical item emerging in the group } / 3 .
\end{array}
\end{aligned}
$$

There were two relevant comparisons: (1) between hits in the experimental and control conditions and (2) between critical false alarms and base rates (see Table 4). We

\begin{tabular}{|c|c|c|c|c|}
\hline \multirow[b]{2}{*}{ Measure } & \multicolumn{2}{|c|}{ Recognition } & \multicolumn{2}{|c|}{ Confidence } \\
\hline & $M$ & $S D$ & $M$ & $S D$ \\
\hline \multicolumn{5}{|c|}{ Experimental Condition } \\
\hline Hits & .74 & .22 & 5.24 & 0.86 \\
\hline Critical false alarms & .21 & .23 & 4.26 & 1.06 \\
\hline Random false alarms & .05 & .08 & 3.06 & 1.54 \\
\hline Base rate & .14 & .13 & - & \\
\hline Mean no. of versions selected & 3.07 & 0.45 & - & \\
\hline \multicolumn{5}{|c|}{ Control Condition } \\
\hline Hits & .82 & .16 & 5.32 & 0.68 \\
\hline Random false alarms & .18 & .03 & 3.34 & 1.33 \\
\hline Mean no. of versions selected & 3.43 & 0.25 & - & \\
\hline
\end{tabular}

Table 4

Recognition Performance and Confidence Ratings

Note-The means for Experiment 4 were adjusted to exclude instances in which the participants failed to respond within $5 \mathrm{sec}$, an average of $6 \%$ of the trials. 
treated individuals as the unit of analysis when comparing hit rates. Intraclass correlations between experimental and control hits were not significant for the group main effect $\left[F(13,40)=1.14, M S_{\mathrm{e}}=459.56, p>.3\right]$ or for the group $\times$ treatment interaction $\left[F(13,40)=1.27, M S_{\mathrm{e}}=\right.$ $250.64, p>$.2]. Paired sample $t$ tests established that the difference between experimental hits and control hits was significant $[t(53)=2.48, p<.05]$. For the comparison between critical false alarms and the base rate, the unit of analysis was groups. The rate of critical false alarms was reliably above the base rate $[t(13)=2.04, p<.05]$. Although other explanations are possible, these results are consistent with those dealing with social contagion (e.g., Meade \& Roediger, 2002): False alarms were more likely to increase following group recounting than following individual recounting. Moreover, the false recognitions were traced to what had been said in the group recounting.

Confidence ratings. We compared the confidence ratings assigned to incidences of hits, critical false alarms, and random false alarms (see Table 4). None of the intraclass correlations was significant at the .20 level, indicating that individual participants could be treated as the unit of analysis. A comparison of means revealed significant differences between confidence ratings for hits and false alarms in the control condition $[t(25)=8.92, p<.01]$, for hits and random false alarms in the experimental condition $[t(25)=7.45, p<.01]$, and for critical false alarms and random false alarms in the experimental condition $[t(14)=3.04, p<.01]$. The difference between confidence ratings for experimental hits and critical false recognitions was only marginally significant $[t(28)=2.05$, $p<.06]$. The presence of a contrasting item in the group recounting not only led to more false alarms in the postgroup recognition test, but also created greater confidence in these false alarms.

Postgroup individual free recall. As with the recognition measures, the analysis of the individual free recall focused on the participants' memory for contrasting items. We first calculated the proportion of critical details recalled (see Table 5). In a two-way ANOVA, we found a significant main effect for condition [experimental vs. control; $\left.F(1,13)=5.54, M S_{\mathrm{e}}=0.05, p<.05\right]$ and a marginal main effect of time [pregroup vs. postgroup; $\left.F(1,13)=4.04, M S_{\mathrm{e}}=0.02, p<.06\right]$.

More pertinent are the false recalls - that is, recalled critical details that were not present in the originally studied story. For the experimental condition, we classified falsely recalled critical items in the postgroup recollec- tions as critical false recalls if they appeared in the group recounting and as random false recalls if they did not. For the control condition, we could look only at what we have defined as random false recalls. We were interested in the proportion of false recalls out of the total number of critical details in the original stories (see Table 5). For the experimental condition, although the proportion of false recalls was small, the proportion of critical false recalls was significantly greater than the proportion of random false recalls $[t(13)=4.56, p<.01]$.

Mnemonic convergence and conversational roles. If postgroup memories converged on a single rendering of the past, group members should have recognized (correctly or incorrectly) fewer versions of a critical detail in the experimental condition than in the control condition. We determined the average number of versions recognized for each critical detail across the 10 critical details. As Table 4 indicates, this average was smaller for the experimental condition than for the control condition $[t(13)=$ 2.63, $p<.03$ ].

As to the recall performance, for each group, we calculated the number of different versions of a critical item across the 4 group members' recollections, first for the pregroup recollections and then for the postgroup recollections. Many of the critical items were never recalled by any group member in their pregroup or postgroup recollections, and few of the items emerged in all four of the pregroup or postgroup recollections. Hence, the number of recalled versions was quite small when averaged across the 10 critical items. For the pregroup recollections, the average number of versions was .98 in the experimental condition and .99 in the control condition; for the postgroup recollections, the average number was .91 in the experimental condition and .99 in the control condition. A two-way ANOVA revealed significant main effects for condition $\left[F(1,13)=20.25, M S_{\mathrm{e}}=0.02, p<.01\right]$ and time $\left[F(1,13)=10.83, M S_{\mathrm{e}}=0.002, p<.01\right]$ and, importantly, a significant interaction between condition and time $\left[F(1,13)=9.03, M S_{\mathrm{e}}=0.002, p<.01\right]$. The group recounting produced fewer recalled versions in the postgroup recollections than one would expect from the control condition, indicating that the conversation led to the further formation of a collective memory.

What about the contribution of the dominant narrator? We followed the procedure outlined in Study 1, using two coders. At all stages of the coding, $\kappa$ on the coders' agreement was .85 or greater. The strongest narrator contributed a greater proportion of the critical details in the group

Table 5

Recall of Critical Items in Pregroup and Postgroup Individual Free Recall, Experiment 2

\begin{tabular}{|c|c|c|c|c|c|c|c|c|}
\hline \multirow[b]{3}{*}{ Measure } & \multicolumn{4}{|c|}{ Experimental } & \multicolumn{4}{|c|}{ Control } \\
\hline & \multicolumn{2}{|c|}{ Pregroup } & \multicolumn{2}{|c|}{ Postgroup } & \multicolumn{2}{|c|}{ Pregroup } & \multicolumn{2}{|c|}{ Postgroup } \\
\hline & $M$ & $S D$ & $M$ & $S D$ & $M$ & $S D$ & $M$ & $S D$ \\
\hline Proportion recalled & .57 & .26 & .63 & .22 & .53 & .26 & .53 & .22 \\
\hline Critical false recall & & & .08 & .05 & & & & \\
\hline Random false recall & .03 & .07 & .03 & .06 & .04 & .08 & .05 & .09 \\
\hline
\end{tabular}


recounting than one would expect from chance alone [the proportion was $.70, S D=.10 ; t(13)=4.67, p<.001]$. As to the postgroup recollections, a group member was more likely to be the source of the critical false alarms as his or her strength as narrator increased. The correlation between the proportion of critical false alarms attributed to what a member recalled in the group recounting and his or her strength as narrator was $r=.31, p<.05$.

These results reinforce those from Study 1. Conversational remembering promoted the formation of a collective memory, and critical false recognitions and critical false recalls were more likely to have as their source the strongest narrator, rather than another group member. Moreover, because of the design and material of Study 2, the role of social contagion in the formation of collective memory is underscored. The pattern of results we found is unlikely to be due to guessing or "social conformity" (Asch, 1956; Binet, 1900). We stressed that we wanted the participants to remember what was in the original material. Moreover, in the recognition test, the participants placed more confidence in their critical false alarms than in their random false alarms.

\section{GENERAL DISCUSSION}

Conversations do not lead inevitably to the formation of a collective memory. At the very least, two criteria in combination are sufficient for a conversation to promote the formation of a collective memory: (1) Unshared pregroup recollections surface in the conversation, and (2) these unshared pregroup recollections "contaminate" the postgroup recollections of other group members. Neither of these conditions is satisfied in every act of conversational remembering, but when they occur, a collective memory will emerge.

Our research indicates that the needed unshared pregroup recollections will be more likely to surface in a group recounting to the degree that a dominant narrator is present. Specifically, Study 1 showed that recollections were more likely to converge on a shared rendering of the past to the extent that the strength of the strongest narrator in a group recounting was markedly greater than the strength as narrator of other group members. Study 2 extended this result not only to recognition, but also to groups of unrelated individuals.

If the conversations recorded here are representative of everyday conversations, a dominant narrator may surface in some, but not all, conversations. Of course, conversations may still facilitate the formation of a collective memory even in the absence of a dominant narrator. A shared pregroup recollection emerging in the group recounting could remind the group of a forgotten pregroup recollection. Moreover, people may simply forget the unshared pregroup recollections in the absence of any rehearsal in the group recounting. Interestingly, under this circumstance, the result would be a postgroup collective memory consisting mainly of shared pregroup recollections (which are likely to be core and central story elements), just as we found for conversations without a dominant narrator.

In focusing on the contribution of a dominant narrator, we have emphasized the degree to which the narrator contributed to the discussion, not the complex social relationships he or she might have had with other group members. In Study 2, we found an effect of narratorship when group members were unrelated. As to the social relationships among the family members in Study 1, they may have been important in determining which family member emerged as a narrator. There probably is, however, no simple criterion by which one could predict, on the basis of these social relationships, who this family member might be. As was noted, the dominant narrators in the high-MSN groups included fathers, mothers, brothers, and sisters (see also Hirst et al., 1997). We did find a positive correlation between the number of words in an individual's pregroup recollection and his or her strength as narrator (cf. Basden et al., 1997). This correlation, however, was a modest .49, indicating that the dominant narrator did not always have the most extensive pregroup recollection. Elsewhere, we have discussed how the personal relevance of a story led a group member to adopt the role of dominant narrator; but again, this effect of relevance was found in some, but not all, of the cases we studied (Hirst \& Manier, 1996; Hirst et al., 1997; Manier, 1997).

Following Stasser and colleagues (Stasser, et al., 1995; Stewart \& Stasser, 1995), one might expect that expertise would predict narratorship. In some instances, expert status might lead a group member to adopt a dominant role. In other instances, however, experts may intentionally limit what they contribute to a conversation - for instance, if they are concerned about confidentiality. Even if experts are more likely to influence postgroup recollections than are nonexperts, it does not follow that they will necessarily become narrators in group recountings, and it will be difficult for them to influence others in a major way without playing a major role in the conversations.

In that collective memories held by a group shape the identity of the group and, in turn, the actions of the group, it is important to understand the conditions under which collective memories are likely to be formed. Such an analysis would explore the interaction between cognitive factors and situational factors. We have mentioned several possible cognitive factors (e.g., in Study 2, the presence of social contagion) and one situational factor (the presence of a narrator). There are undoubtedly other cognitive and situational factors. Nevertheless, on the basis of our findings, we predict that a collective memory is likely to emerge from a conversation if the appropriate cognitive and situational factors align. It is not enough for the conditions to be felicitous for social contagion, and the presence of a dominant narrator will probably not be sufficient if social contagion is in some manner inhibited. Neither of these conditions may be necessary for the formation of a collective memory, but more importantly, neither alone is sufficient. Both dominant narrator and conditions conducive to social contagion 
must be present if either is to serve as a means through which a collective memory is formed.

\section{REFERENCES}

Asch, S. E. (1956). Studies of independence and conformity: A minority of one against a unanimous majority. Psychological Monographs, 70(Whole No. 416).

BANGERTER, A. (2000). Identifying individual and collective acts of remembering in task-related communication. Discourse Processes, $\mathbf{3 0}$ 237-264.

Bangerter, A., von Cranach, M., \& Arn, C. (1997). Collective remembering in the communicative regulation of group action: A functional approach. Journal of Language \& Social Psychology, 16, 365-388.

BAR-TAL, D. (2000). Shared beliefs in a society. Thousand Oaks, CA: Sage.

Basden, B. H., Basden, D. R., Bryner, S., \& Thomas, R. L., III (1997). A comparison of group and individual remembering: Does collaboration disrupt retrieval strategies? Journal of Experimental Psychology: Learning, Memory, \& Cognition, 23, 1176-1191.

Basden, B. H., Basden, D. R., \& Henry, S. (2000). Cost and benefits of collaborative remembering. Applied Cognitive Psychology, 14, 497-507.

Basden, B. H., Reysen, M. B., \& Basden, D. R. (2002). Transmitting false memories in social groups. American Journal of Psychology, 115, 211-231

BELLI, R. F. (1988). Color blend retrievals: Compromise memories or deliberate compromise responses? Memory \& Cognition, 16, 314326.

Binet, A. (1900). La suggestibilité. Paris: Schleicher Freres.

Coelho, P. (1993). The alchemist. New York: Harper \& Row.

Dritschel, B. H. (1991). Autobiographical memory in natural discourse: A methodological note. Applied Cognitive Psychology, 5, 319-330.

EChTERHOFF, G., \& SAAR, M. (Eds.) (2002). Kontexte und Kulturen des Erinnerns. Konstanz: UVK.

FAY, N., GARROD, S., \& CARLETTA, J. (2000). Group discussion as interactive dialogue or as serial monologue: The influence of group size. Psychological Science, 11, 481-486.

Fentress, J., \& WickHAm, C. (1992). Social memory. Cambridge, MA: Blackwell.

FLEISS, J. L. (1981). Statistical methods for rates and proportions. New York: Wiley.

Gabbert, F., Memon, A., \& Allan, K. (2003). Memory conformity: Can eyewitnesses influence each other's memory for an event? Applied Cognitive Psychology, 17, 533-543.

Gladwell, M. (2002). The tipping point: How little things can make a big difference. New York: Back Bay Books.

Halbwachs, M. (1980). Collective memory. New York: Harper \& Row.

Hirst, W., \& Manier, D. (1996). Social influences on remembering. In D. Rubin (Ed.), Remembering the past (pp. 271-290). New York: Cambridge University Press.

Hirst, W., \& MANIER, D. (2002). The diverse forms of collective memory. In G. Echterhoff \& M. Saar (Eds.), Kontexte und Kulturen des Erinnerns (pp. 75-102). Konstanz: UVK.

Hirst, W., Manier, D., \& Apetroaia, I. (1997). The social construction of the remembered self: Family recounting. In J. G. Snodgrass \& R. L. Thompson (Eds.), The self across psychology (Annals of the New York Academy of Sciences, Vol. 818, pp. 163-188). New York: New York Academy of Sciences.

Jerome, J. K. (1900). Three men on the bummel. Bristol: Arrowsmith.

Kashy, D. A., \& KennY, D. A. (2000). The analysis of data from dyads and groups. In H. T. Reis \& C. M. Judd (Eds.), Handbook of research methods in social and personality psychology (pp. 451-477). New York: Cambridge University Press.

KInTSCH, W. (1976). Memory for prose. In C. N. Cofer (Ed.), The structure of human memory (pp. 90-113). San Francisco: Freeman.

LofTUs, E. F. (1993). Made in memory: Distortion in memory after misleading communication. In D. L. Medin (Ed.), The psychology of learning and motivation: Advances in research and theory (Vol. 30, pp. 187-215). San Diego: Academic Press.

MANIER, D. (1997). Family remembering: Autobiographical remembering in the context of family conversations. Dissertation Abstracts International, 58(5-B), 2688. (University Microfilms No. 9732474)

Manier, D., Pinner, E., \& Hirst, W. (1996). Conversational remembering. In D. Hermann, C. McEvoy, C. Hertzog, P. Hertel, \& M. K. Johnson (Eds.), Basic and applied memory research: Practical applications (Vol. 2, pp. 269-286). Hillsdale, NJ: Erlbaum.

McCann, C. D., \& Higgins, R. (1992). Personal and contextual factors in communication: A review of the "communication game." In G. R. Stein \& K. Fiedler (Eds.), Language, interaction, and social cognition (pp. 144-172). London: Sage.

Meade, M. L., \& Roediger, H. L., III (2002). Explorations in the social contagion of memory. Memory \& Cognition, 30, 995-1009.

Middleton, D., \& Edwards, D. (Eds.) (1990). Collective remembering. London: Sage.

Moreland, R. L., Argote, L., \& Krishman, R. (1996). Socially shared cognition at work: Transactive memory and group performance. In J. L. Nye \& A. M. Brower (Eds.), What's social about social cognition? Research on socially shared cognition in small groups (pp. 5786). Thousand Oaks, CA: Sage.

OLICK, J. K. (1999). Collective memory: The two cultures. Sociological Theory, 7, 333-348.

Olick, J. K., \& Robbins, J. (1998). Social memory studies: From "collective memory" to the historical sociology of mnemonic practices. Annual Review of Sociology, 24, 105-140.

Ozuru, Y., \& Hirst, W. (2002, November). Conversational influence on recognition memory. Poster presented at 43rd Annual Meeting of the Psychonomic Society, Kansas City, MO.

PASUPATHI, M. (2001). The social construction of the personal past and its implications for adult development. Psychological Bulletin, 127, 651-672.

Pennebaker, J. W., Paez, D., \& Rime, B. (Eds.) (1997). Collective memory of political events. Mahwah, NJ: Erlbaum.

Roediger, H. L., III, Meade, M. L., \& Bergman, E. T. (2001). Social contagion of memory. Psychonomic Bulletin \& Review, 8, 365-371.

SHERIF, M. (1966). The psychology of social norms. New York: Harper \& Row.

SPERBER, D. (1996). Explaining culture: A naturalistic approach. Cambridge, MA: Blackwell.

Stasser, G., Stewart, D. D., \& Wittenbaum, G. M. (1995). Expert roles and information exchange during discussion: The importance of knowing who knows what. Journal of Experimental Social Psychology, 31, 244-265.

Stasser, G., \& Titus, W. (1987). Effects of information load and percentage of shared information on the dissemination of unshared information during group discussion. Journal of Personality \& Social Psychology, 53, 81-93.

Stewart, D. D., \& Stasser, G. (1995). Expert role assignment and information sampling during collective recall and decision making. Journal of Personality \& Social Psychology, 69, 619-628.

Tindale, R. S., \& ShefFey, S. (2002). Shared information, cognitive load, and group memory. Group Processes \& Intergroup Relations, 5, 5-18.

Todorov, A., Lalljee, M., \& Hirst, W. (2000). Communication context, explanation, and social judgment. European Journal of Social Psychology, 30, 199-209.

Walther, E., Bless, H., Strack, F., Rackstraw, P., Wagner, D., \& WeRTH, L. (2002). Conformity effects in memory as a function of group size, dissenters and uncertainty. Applied Cognitive Psychology, 16, 793-810.

WEGNER, D. (1986). Transactive memory: A contemporary analysis of the group mind. In B. Mullen \& G. Goethals (Eds.), Theories of group behavior (pp. 185-208). New York: Springer.

Wegner, D., Erber, R., \& Raymond, P. (1991). Transactive memory in close relationships. Journal of Personality \& Social Psychology, 6, 923-929. 
Weldon, M. S. (2001). Remembering as a social process. In G. H. Bower (Ed.), The psychology of learning and motivation (Vol. 40, pp. 67-120). New York: Academic Press.

Weldon, M. S., \& Bellinger, K. D. (1997). Collective memory: Collaborative and individual processes in remembering. Journal of Experimental Psychology: Learning, Memory, \& Cognition, 23, 1160-1175.

Weldon, M. S., Blair, C., \& Huebsch, P. D. (2000). Group remembering: Does social loafing underlie collaborative inhibition? Journal of Experimental Psychology: Learning, Memory, \& Cognition, 6, 15681577.

Wertsch, J. (2002). Voices of collective remembering. New York: Cambridge University Press.

Wilkes-Gibbs, D., \& Kim, P. H. (1991, November). Discourse influences on memory for visual forms. Paper presented at the 32nd Annual Meeting of the Psychonomic Society, San Francisco.
Wittenbaum, G. M., \& Park, E. S. (2001). The collective preference for shared information. Current Directions in Psychological Science, 10, 70-73.

Wittenbaum, G. M., \& Stasser, G. (1996). Management of information in small groups. In J. L. Nye \& A. M. Brower (Eds.), What's social about social cognition? Social cognition research in small groups (pp. 3-28). Thousand Oaks, CA: Sage.

Wright, D. B., Self, G., \& Justice, C. (2000). Memory conformity: Exploring the misinformation effects when presented by another person. British Journal of Psychology, 91, 189-202.

(Manuscript received December 7, 2004; revision accepted for publication May 10, 2005.) 